\title{
Hypertension and Management
}

\section{Medication Adherence and Associated Factors in Management of Hypertension in Shashemene Referral Hospital, Ethiopia}

\author{
Gemmechu Hasen ${ }^{1^{*}}$ and Awel Abdo \\ ${ }^{1}$ School of Pharmacy, Institute of Health, Jimma University, Jimma, Ethiopia \\ ${ }^{2}$ Shashemene Referral Hospital, Westi Arsi, Ethiopia
}

*Corresponding author: Gemmechu Hasen, School of Pharmacy, Institute of Health, Jimma University, Jimma, Ethiopia, Tel: +251-916-973-323

\begin{abstract}
Background: Despite the availability of effective treatment, over half of the patients being treated for hypertension drop out of care entirely within a year of diagnosis. Adherence to antihypertensive medication is an effective step for controlling blood pressure and preventing complications. This study is aimed to assess medication adherence and associated factors in the management of hypertension in Shashemene Referral Hospital, South Ethiopia.

Methods: Hospital-based cross-sectional study was conducted to assess medication adherence and associated factors among 197 hypertensive patients on treatments at Shashemene Referral Hospital. A simple random sampling technique was used to select the study participants from the study population. Sociodemographic data, medication adherence, factors affecting adherence were collected using a structured questionnaire and an 8-item Morisky medication adherence scale. The collected data were processed and analyzed using SPSS version 20. Chi-square was used to determine the association between the level of medication adherence and socio-demographic characteristics of hypertensive patients at a $5 \%(p<0.05)$ level of significance.
\end{abstract}

Results: Among 197 respondents 123 (62.6\%) were males and the mean age was $47 \pm 13$ years. From a total of 197 study participants, $125(63.5 \%)$ of respondents were adherent to their prescribed medication and the rest were non-adherents. Factors such as occupation $(p=0.033)$, and source of medical service or treatments $(p=0.037)$, were associated with antihypertensive medication adherence. Moreover, there is a significant association between adherence and blood pressure control $(p=0, p<0.05)$. Among study subjects with uncontrolled blood pressure, 50 (25.5\%) respondents had low adherence to antihypertensive medications, and the remaining subjects 31 (15.7\%), 13 (6.7\%) had medium adherence, and high adherence respectively.
Conclusions: More than half of the study participants were found to be adherent to their treatments according to the 8-item Morisky medication adherence scale. Occupational status and source of medical service or treatments were the most common factors associated with antihypertensive medication adherence. Moreover, the status of blood pressure control was significantly associated with the pattern of adherence.

\section{Keywords}

Adherence, Hypertensive patients, BP control, Shashemene

\begin{abstract}
Abbreviations
BP: Blood pressure; CHF: Congestive heart failure; DM: Diabetes mellitus; HTN: Hypertension; HIV: Human immunodeficiency virus; JU: Jimma university; MMAS-8: Morisky's 8-item medication adherence scale; SRH: Shashemene referral hospital; TB: Tuberculosis
\end{abstract}

\section{Background}

Hypertension is defined as persistent elevation of systolic BP of $140 \mathrm{mmHg}$ or greater and/or diastolic BP of $90 \mathrm{mmHg}$ or greater, and it is a public-health challenge worldwide [1]. Detection, prevention, treatment, and control of this condition should receive high priority, and analysis of the global burden of hypertension revealed that over $26 \%$ of the world's adult population had hypertension in 2000 , and the proportion is expected to increase to $29 \%$ by 2025 [2]. It is also one of the main risk factors for the development of renal complications, cardiac and cerebrovascular diseases, and strongly impacting social security, due to its high medical and so-

Citation: Hasen G, Abdo A (2020) Medication Adherence and Associated Factors in Management of Hypertension in Shashemene Referral Hospital, Ethiopia. J Hypertens Manag 6:054. doi. org/10.23937/2474-3690/1510054

Accepted: December 24, 2020: Published: December 26, 2020

Copyright: (C) 2020 Hasen G, et al. This is an open-access article distributed under the terms of the Creative Commons Attribution License, which permits unrestricted use, distribution, and reproduction in any medium, provided the original author and source are credited. 
cioeconomic costs, especially complications that accompany it [3]. On the other hand, despite the availability of effective treatment, over half of the patients being treated for hypertension drop out of care entirely within a year of diagnosis and of those who remain under medical supervision only about $50 \%$ take at least $80 \%$ of their prescribed medications, and approximately $75 \%$ of patients with a diagnosis of hypertension do not achieve optimum blood-pressure control $[4,5]$. Poor medication adherence to antihypertensive patients can lead to suboptimal control of blood pressure, and result in further medical and psychosocial complications, reduction in quality of life, and wastage of health care resources, which are potential burdens on the healthcare system [6]. Moreover, poor adherence to antihypertensive has been attributed to long duration of treatment, unnecessary over-prescription of drugs, substantial worsening of diseases, avoidable increases in hospital admission rates, longer hospital stays, leading to a significant medical burden, particularly in low income countries [7]. For instance, study conducted in different hospital of Ethiopia includes, Tikur Anbessa Specialized Hospital renal unit in Addis Ababa, Dessie Referral Hospital, and Yirgalem Hospital revealed that $69.2 \%, 68.13 \%$, and $40 \%$ non-adherent to the prescribed antihypertensive medication respectively [8-10]. According to these report losing of hope, use of social drug, economics problems, forgetfulness and lack of money were the major factor associated with non-adherence. In order to mitigate the effects of the disease in populations, it is essential to improve adherence among sufferers of the disease by identifying underlying factors in order to mitigating against adherence behavior and developing effective interventions to overcome identified factors [11]. To current knowledge of the authors there are no previous studies that examined adherence with antihypertensive medication or the characteristics of the non-adherent patients in Shashemene. Therefore, the present study is aimed to assess medication adherence and associated factors in management of hypertension in Shashemene Referral Hospital, South Ethiopia.

\section{Methods and Materials}

\section{Study design, period and area}

The cross-sectional study design was conducted at Shashemene referral hospital from February to March 2019 at Shashemene Referral Hospital (SRH). Shashemene is located $250 \mathrm{~km}$ from Addis Ababa on the way to Hawasa and it is found in west Arsi zone of Oromia regional state. SRH serves a population of eight million in Oromia and neighboring South Ethiopian communities. Hospital possesses different types of departments which include Pediatrics, Internal medicine, Gynobstristics, and Surgery. The Hospital also has also other departments like Psychiatry, Ophthalmology, Dermatology, and Neurology. The hospital has TB-HIV clinic and MDR-TB clinic separately. And others like DM, CHF, HTN currently has no clinic separately, but they patients follow at different OPD (Out Patient Department) which is separated as case 1-6 in OPD.

\section{Population}

Source population: All hypertensive patients attending at Shashemene Referral Hospital of medical Outpatient department for treatment follow up.

Study population: All adult hypertensive patients who are greater than 18-years-old, and on follow up for at least six month and visiting the hospital during the study period fulfilling inclusion criteria at Shashemene Referral Hospital.

\section{Sample size and sampling technique}

Sample size: The sample size for the study was determined using the following formula [11].

$$
n_{i}=\frac{(Z \alpha / 2)^{2} p(1-q)}{d^{2}}
$$

Where:

$$
\begin{aligned}
& \quad n_{i} \text { - The initial sample size required } \\
& \quad \mathrm{p} \text { - Prevalence of adherence (64.5\%) [11] } \\
& \text { * } \mathrm{d} \text { - The margin of sampling error tolerated (5\%) } \\
& \text { * } \quad Z \alpha / 2 \text { - Percentage confidence level (1.96) }
\end{aligned}
$$

Therefore, the sample size is:

$$
n=\frac{(1.96)^{2} 0.645(1-0.645)}{(0.05)^{2}}=351
$$

Since our source population is less than 10,000 , which are 450 we use the correction formula as follows.

$$
\begin{aligned}
& n_{f}=\frac{n}{1+\frac{n}{N}} \quad \begin{array}{l}
\text { Where, } \\
\mathrm{n}_{\mathrm{f}}=\text { Final sample size } \\
\mathrm{n}=\text { Total study population which is } 351 \\
\mathrm{~N}=\text { Source of population which is } 450
\end{array} \\
& n_{f}=\frac{351}{1+\frac{351}{450}}=197
\end{aligned}
$$

Sampling technique: All patients attending hypertension clinics who had fulfilled inclusion criteria were interviewed until desired sample were obtained.

\section{Study variable}

\section{Independent variables}

Sociodemographic characteristics like age, gender, sex, occupational status, educational status, religion, ethnicity, monthly income, marital status, source of medical service or treatments and duration of treatment.

\section{Dependent variable}

Pattern of adherence towards antihypertensive medications and blood pressure control.

\section{Inclusion and exclusion criteria}

Inclusion criteria 
All adult hypertensive patients those are greater than 18-years-old, and on follow up for at least six months duration and on medication during the study period.

\section{Exclusion criteria}

All patients who are critically ill or psychiatric patients.

\section{Data Collection Procedure}

\section{Instrument}

Data was collected by using Morisky's 8-item Medication Adherence Scale $[12,13]$ to assess magnitude of non-adherence, and standard questionnaire consisting closed question to address factor affecting adherence to antihypertensive medications.

\section{Data collection method}

At each OPD rooms selected data collectors were identified participants who fulfill the criteria to be involved in the study while they exit after they got service. Using standard questionnaires and Morisky's 8-item Medication Adherence Scale data collectors were interviewed targeted hypertensive patients during their exit from the OPD after they got service. During interview other patients were separated to not hear others response to avoid bias.

\section{Data analysis procedure}

Data was collected, and the patient responses was cleared, entered in to a computer and relevantly organized and percentage with computer and present in table and chart. Statistical significance test was applied to reflect the association between the variables by using statistical package for social science version 20 (SPSS version-20). Accordingly, chi-square was used to determine the association between the level of medication adherence and socio-demographic characteristics of hypertensive patients at a $5 \%(p<0.05)$ level of significance.

\section{Data quality control}

During data collection supervision was carried out and daily checking of the collected data was made by principal investigator. To assure data quality, pretest was conducted; data collectors were recruited; training and orientation were given to data collectors.

\section{Operational Definition}

\section{Adherence}

Is defined as "the extent to which a person's behavior- taking medication, following a diet, and/or executing lifestyle changes corresponds with agreed recommendations from a health care provider" [6].

\section{Hypertension}

Is defined as the persistent systolic blood pressure equal to and greater than $140 \mathrm{mmHg}$ and/or persistent diastolic blood pressure equal to and greater than 90 $\mathrm{mmHg}$ [1].

\section{Hypertensive patient}

Refers to a person diagnosed with hypertension as defined above.

\section{Non-adherence}

Any form of deviation from adherence like losing one appointment, missing doses [6].

\section{Ethical Considerations}

Jimma University Institutional Review Board approved the research. A formal letter was obtained from the Department of Pharmacy, college of Health Sciences and permission was obtained from Shashemene Referral Hospital, Oromia, and West Arsi, to collect data. The concerned hospital was also assured that the data was kept confidential. Each respondent who was interviewed was asked to give their consent after explaining the purpose, objective, and benefit of the study. Then respondents, who were volunteers, were interviewed. The participants were free to withdraw from the interview at any stage without incurring any consequences.

\section{Results}

Among 197 respondents 123 (62.6\%) were males and mean age was $47 \pm 13$ year. Among study respondents $44(22.33 \%)$ were age between $45-49$ years, and followed by 37 (18.78\%) which belongs to age between 35-39, and average mean, and standard deviation were $47.2,12.88$ respectively. Larger proportions of respondents started their medications 1-3 years 140 (71.06\%) back, and small proportion of respondents 4 (2.03\%) were started $>6$ years back. Among study participants $102(51.7 \%)$ were Muslim, followed by orthodox 66 (33.5\%). From study participants 155 (78.7\%) of respondents were married, while $26(13.2 \%)$ were divorced. Larger proportions of respondents 111 (56.3\%) were illiterate. Among study subjects 55 (27.9\%) of the respondents had 446-1200 birr of monthly income while others respondents 27 (13.7\%), 6 (3.04\%), 17 (6.1\%) had 1201-2500, 2501-3500, and greater than 3501 respectively. But, remaining respondents 94 (47.7\%) do not know their monthly income in money. Among study subjects 85 (43.14\%) of respondents were farmers. Larger proportions of respondents 167 (84.8\%) had no family support (Table 1 ).

Moreover, from total of 7 respondents who had poor patients awareness on the importance of adherence to antihypertensive medications 4 (57.1\%) were because of its rules are difficult, and the rest were due to had no idea (Figure 1). From study participants large proportion $93(47.3 \%)$ of them had medium adherence to antihypertensive medications and the remaining respondents had $36.5 \%, 16.2 \%$ low adherence and high adherence respectively (Figure 2 ). The level of adheren- 
Table 1: Socio-demographic characteristics of respondents in SRH Ethiopia, 2019.

\begin{tabular}{|c|c|c|c|}
\hline Variables & & Frequency & Percentages \\
\hline Gender & Male & 123 & 162.6 \\
\hline & Female & 74 & 37.4 \\
\hline Age & $15-19$ & 1 & 0.5 \\
\hline & $20-24$ & 5 & 2.5 \\
\hline & $25-29$ & 9 & 4.6 \\
\hline & $30-34$ & 10 & 15.1 \\
\hline & $35-39$ & 37 & 18.8 \\
\hline & $40-44$ & 14 & 17.1 \\
\hline & $45-49$ & 44 & 22.3 \\
\hline & $50-54$ & 19 & 9.6 \\
\hline & $55-59$ & 25 & 12.7 \\
\hline & $60-64$ & 15 & 7.6 \\
\hline & $>65$ & 18 & 9.1 \\
\hline Duration of & 6-11 months & 21 & 10.6 \\
\hline treatment & $1-3$ years & 140 & 71.1 \\
\hline & 4-6 years & 32 & 16.2 \\
\hline & Above 6 years & 4 & 2.03 \\
\hline Marital status & Married & 155 & 78.7 \\
\hline & Single & 12 & 6.1 \\
\hline & Divorced & 26 & 13.2 \\
\hline & Widowed & 4 & 2.03 \\
\hline Religion & Protestant & 29 & 14.7 \\
\hline & Orthodox & 66 & 33.5 \\
\hline & Muslim & 102 & 51.7 \\
\hline
\end{tabular}

\begin{tabular}{|c|c|c|c|}
\hline \multirow{5}{*}{$\begin{array}{l}\text { Educational } \\
\text { level }\end{array}$} & Illiterate & 111 & 56.3 \\
\hline & $\begin{array}{l}\text { Read and } \\
\text { write }\end{array}$ & 41 & 20.8 \\
\hline & Primary & 8 & 4.06 \\
\hline & Secondary & 10 & 5.1 \\
\hline & $\begin{array}{l}\text { Above } \\
\text { secondary }\end{array}$ & 27 & 13.7 \\
\hline \multirow[t]{6}{*}{ Occupation } & Housewife & 38 & 19.3 \\
\hline & Employed & 25 & 12.7 \\
\hline & Farmer & 85 & 43 \\
\hline & Daily labor & 5 & 2.5 \\
\hline & Merchant & 40 & 20.3 \\
\hline & Other & 4 & 2.03 \\
\hline \multirow[t]{4}{*}{ Ethnicity } & Oromo & 133 & 67.5 \\
\hline & Amhara & 41 & 20.8 \\
\hline & Gurage & 21 & 10.6 \\
\hline & Other & 2 & 1.01 \\
\hline \multirow{6}{*}{$\begin{array}{l}\text { Monthly } \\
\text { income }\end{array}$} & $<445$ & 3 & 1.52 \\
\hline & $446-1200$ & 55 & 27.9 \\
\hline & $1201-2500$ & 27 & 13.7 \\
\hline & $2501-3500$ & 6 & 3.04 \\
\hline & $>=3501$ & 12 & 6.1 \\
\hline & $\begin{array}{l}\text { Un able to } \\
\text { specify }\end{array}$ & 94 & 47.7 \\
\hline \multirow{2}{*}{$\begin{array}{l}\text { Family } \\
\text { support }\end{array}$} & No & 167 & 84.8 \\
\hline & Yes & 30 & 15.2 \\
\hline
\end{tabular}

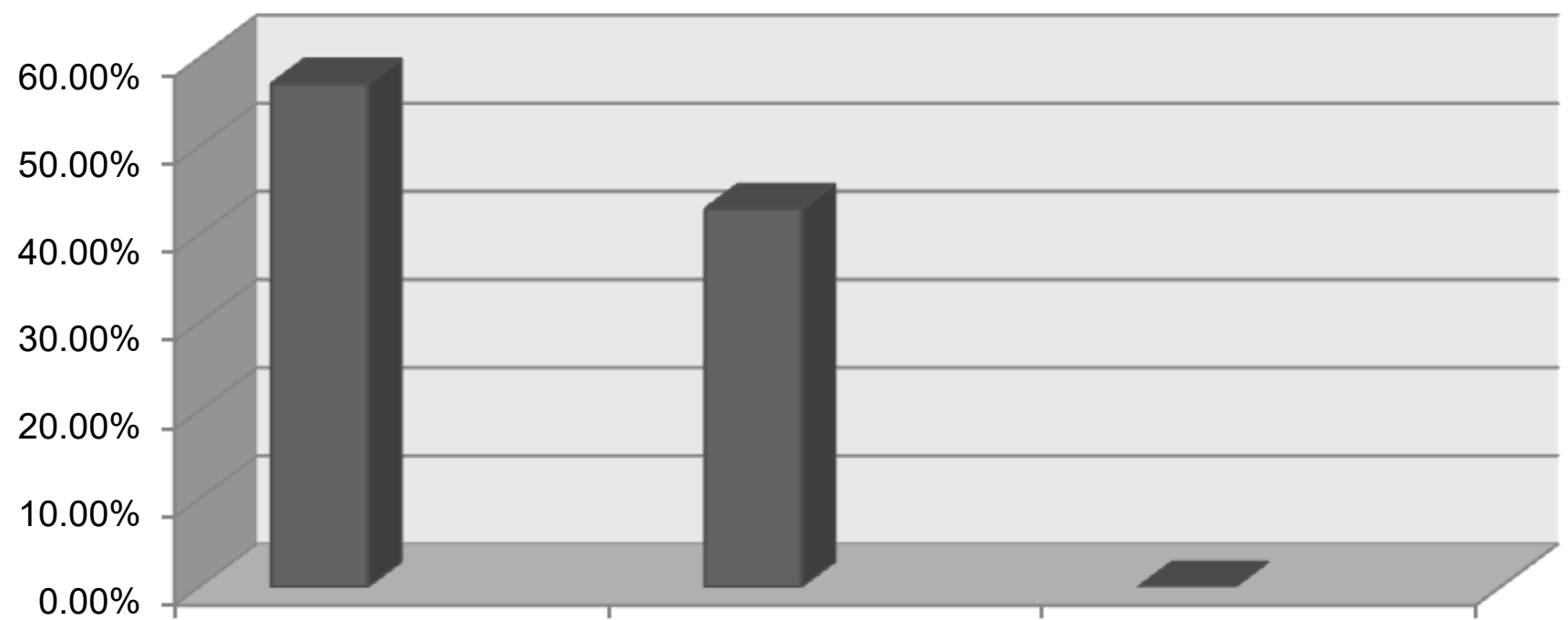

its rule are difficult

I have no idea

had no importance

Figure 1: Reason for poor patient awareness on the importance of adherence to antihypertensive medications in SRH, Ethiopia, 2019.

ce was determined based on Morisky Medication Scale (MMS) value classification (1-2 = Medium adherence, 3-8 $=$ Low adherence, $0=$ High adherence) [14].
From total of study participants, who had irregular follow up due to patients related factor, 21 (42.9\%) of respondents were due to forgetfulness, and the left were lack of money 15 (30.6\%) and negligence (26.5\%) (Table 2). 


\section{Magnitude of adherence}
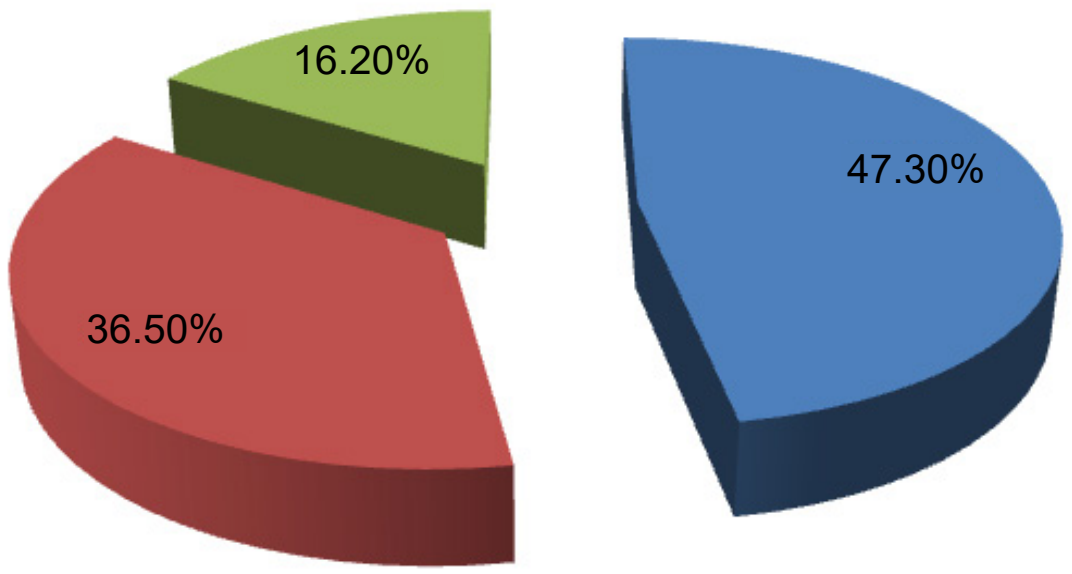

medium adherence

low adherence

high adherence

Figure 2: Magnitude of adherence in study participants in SRH, Ethiopia, 2019.

Table 2: Patients related factors that lead to irregular follow up among study participants in SRH, Ethiopia, 2019.

\begin{tabular}{|l|l|l|l|}
\hline S.N & Patients related factor & $\begin{array}{l}\text { Number of respondents that had no } \\
\text { regular follow up }\end{array}$ & Percentages (\%) \\
\hline 1 & Lack of money & 15 & 30.6 \\
\hline 2 & Forgetfulness & 21 & 42.9 \\
\hline 3 & Negligence & 13 & 26.5 \\
\hline
\end{tabular}

Table 3: Treatments related factors that lead to irregular follow up among study participants in SRH, Ethiopia, 2019.

\begin{tabular}{|l|l|l|l|}
\hline S.N & Treatment related factor & $\begin{array}{l}\text { Number of respondents that } \\
\text { had no regular follow up }\end{array}$ & Percentages (\%) \\
\hline 1 & Different kinds of drugs & 3 & 7.1 \\
\hline 2 & Adverse effects of drugs & 3 & 7.1 \\
\hline 3 & Unpleasant odor/test & 1 & 2.4 \\
\hline 4 & Prolonged duration of treatment & 34 & 81 \\
\hline 5 & Lack of role of health workers in describing about drug & 1 & 2.4 \\
\hline
\end{tabular}

Table 4: Effects of adherence on BP control among study population in SRH, Ethiopia, 2019.

\begin{tabular}{|c|c|c|c|}
\hline \multirow[t]{2}{*}{ Status of adherence(MMS value) ${ }^{* *}$} & \multicolumn{2}{|c|}{ Blood pressure status ${ }^{*}$} & \multirow[b]{2}{*}{ Total } \\
\hline & Controlled & Uncontrolled & \\
\hline High adherence $(0)$ & $19(9.6 \%)$ & $13(6.7 \%)$ & $32(16.2 \%)$ \\
\hline Medium adherence (1-2) & $62(31.6 \%)$ & $31(15.7 \%)$ & $93(47.2 \%)$ \\
\hline Low adherence (3-8) & $22(11.2 \%)$ & $50(25.3 \%)$ & $72(36.5 \%)$ \\
\hline
\end{tabular}

${ }^{*} B P<140 / 90$ considered as controlled and $>140 / 90$ uncontrolled based SRH diagnosing criteria. Stated after average BP was calculated one from past one from current.

"MMS value classification.

From the study participants the prolonged duration of the treatment $34(81 \%)$ was a major treatment related factor that leads to irregular follow up. Other respondents that had not regular follow up due to treatment related factors such as adverse effect of the drug, different kind of medicine, and lack of the role health worker were $3(7.1 \%), 3(7.1 \%)$, and 1 (2.4\%), respectively (Table 3$)$.
From total of study participants 103 (52.3\%) respondents had controlled blood pressure, and the remaining respondents $94(47.7 \%)$ had controlled blood pressure. Among subjects with uncontrolled blood pressure majority of respondents $50(25.5 \%)$ had low adherence to antihypertensive medications, and the remaining subjects 31 (15.7\%), 13 (6.7\%) had medium adherence, and high adherence respectively. Among subjects with controlled blood pressure majority of respondents 62 
(31.6\%) had medium adherence to antihypertensive medications, and the remaining subjects $22(11.2 \%), 19$ (9.6\%) had low adherence and high adherence respectively (Table 4).

In this study there is significant association between occupation ( $p=0.033)$, source of medical service or treatments $(p=0.037)$ (Table 5). Moreover, there is significant association between adherence and blood pressure control $(p=0, p<0.05)$. Majority respondents who had low adherence belong to uncontrolled blood pressure (Table 6).

\section{Discussions}

From total of 197 study subjects, $63.5 \%$ of respondents were adherent to their prescribed medications.
When compared to study carried out in 140 adult patients with hypertension who have been on treatment for at least 6 months at the primary care clinic of Federal Medical Centre, Umuahia, Nigeria that show (42.9\%) out of 140 patients were adherent, it had higher adherence [15]. This could be due to measurement of adherence were based on different criteria (MMAS-4 Score vs. MMAS-8 Score). However, this study reports a lower adherence as compared to study reported previously in local studies conducted at university of Gondar hospital \& black lion hospital, Addis Ababa, 64.6\% \& 69.5\% respectively $[8,11]$. This might be due to better access and care to patients in these facilities. Magnitude of adherence of this study was within a limit range of WHO prediction which stated that despite the availability of

Table 5: Association between socio-demographic data and respondents with adherence status in SRH, Ethiopia, 2019.

\begin{tabular}{|c|c|c|c|c|c|}
\hline & & \multirow[b]{2}{*}{ Frequency } & \multicolumn{2}{|c|}{ Status of adherence ${ }^{* *}$} & \multirow[b]{2}{*}{$P$ value } \\
\hline \multicolumn{2}{|l|}{ Variables } & & Adherent & Non adherent & \\
\hline \multirow[t]{4}{*}{ Duration of treatment } & 6-11 months & 21 & 2 & 4 & \multirow[t]{4}{*}{$P=0.281$} \\
\hline & $1-3$ years & 140 & 79 & 35 & \\
\hline & 4-6 years & 32 & 33 & 26 & \\
\hline & Above 6 years & 4 & 11 & 7 & \\
\hline \multirow[t]{4}{*}{ Marital status } & Married & 155 & 96 & 59 & \multirow[t]{4}{*}{$P=0.102$} \\
\hline & Single & 12 & 5 & 7 & \\
\hline & Divorced & 26 & 21 & 5 & \\
\hline & Widowed & 4 & 3 & 1 & \\
\hline \multirow[t]{5}{*}{ Educational level } & Illiterate & 111 & 75 & 36 & \multirow[t]{5}{*}{$P=0.233$} \\
\hline & Read and write & 41 & 24 & 17 & \\
\hline & Primary & 8 & 7 & 1 & \\
\hline & Secondary & 10 & 5 & 5 & \\
\hline & Above secondary & 27 & 14 & 13 & \\
\hline \multirow[t]{6}{*}{ Occupation } & House wife & 38 & 19 & 19 & \multirow[t]{6}{*}{$P=0.033^{*}$} \\
\hline & Employed & 25 & 13 & 12 & \\
\hline & Farmer & 85 & 64 & 23 & \\
\hline & Daily labor & 5 & 2 & 3 & \\
\hline & Merchant & 40 & 28 & 12 & \\
\hline & Other & 4 & 1 & 3 & \\
\hline \multirow[t]{2}{*}{ Family support } & Yes & 167 & 107 & 60 & \multirow[t]{2}{*}{$P=0.670$} \\
\hline & No & 30 & 18 & 12 & \\
\hline \multirow{2}{*}{$\begin{array}{l}\text { Source of medical service or } \\
\text { treatments }\end{array}$} & By payments & 181 & 111 & 70 & \multirow[t]{2}{*}{$P=0.037$} \\
\hline & Free payments & 16 & 14 & 2 & \\
\hline
\end{tabular}

"Statistically Significant.

*Status of adherence, 0-2 adherents, 3-8 non adherents.

Table 6: Association between adherence and status of blood pressure in SRH, Ethiopia, 2019.

\begin{tabular}{|l|l|l|l|l|}
\hline Adherence & Frequency & \multicolumn{2}{|c|}{ BP status } & P value \\
\cline { 3 - 4 } & & Controlled & Uncontrolled & \\
\hline High adherence & 32 & 19 & 13 & P = 0* \\
\hline Medium adherence & 93 & 62 & 31 & \\
\hline Low adherence & 72 & 22 & 50 & \\
\hline
\end{tabular}

Significant ${ }^{*}<0.05$ 
effective treatment, over half of the patients being treated for hypertension drop out of care entirely within a year of diagnosis and of those who remain under medical supervision only about $50 \%$ take at least $80 \%$ of their prescribed medications $[6,16]$. This study also showed the magnitude of patient related factor of non-adherence with lack of money, forgetfulness, and negligence were $15(30.6 \%), 21(42.9 \%)$ and $13(26.5 \%)$ respectively. When compared with study conducted in Dharan Municipality of Eastern region of Nepal that show forgetfulness (55\%), lack of money (9.7\%), forgetfulness was comparably less and lack of money was higher [17]. As reported in sociodemographic data majority of study subjects were involved in trading such that possibly this lead to forgetfulness due to work load. However, study done in Praslin Island show that lack of money, forgetfulness, and negligence were $21.8 \%, 18.81 \%$ and $16.83 \%$ respectively was relatively comparable [16]. Factors such as occupation ( $p=0.033)$, and source of medical service or treatments $(p=0.037)$, were associated antihypertensive medication adherence.Moreover, among subjects with controlled blood pressure majority of respondents $31.6 \%$ had medium adherence to antihypertensive medications, and the remaining subjects $11.2 \%, 9.6 \%$ had low adherence and high adherence respectively. BP control was significantly higher in those that adhered to antihypertensive medication compared with non-adhering patients $(p=0,<0.05)$. When compared to study carried out in Federal Medical Centre, Umuahia, Nigeria that show among 49 patients who had good BP control, 45 (91.8\%) were adherent whilst 4 (8.2\%) were not adherent it was relatively low. BP control was significantly higher in those that adhered to antihypertensive medication compared with non-adhering patients ( $p$-value $=0.03$ ) [15]. This difference might occur due to different method of assessing blood pressure control to classify as controlled or uncontrolled.

\section{Study Limitations}

This study have the following limitations: Self-reporting was used as the only method of measuring adherence. This method has the disadvantages of recall bias and eliciting only socially acceptable responses and hence, may overestimate the level of adherence. In addition, it did not consider HTN patients who did not visit the hospital during the time of the study. Hence, the extent of generalizability is limited only to those similar patients who are on chronic illness follow up care.

\section{Conclusions}

More than half of the study participants were found to be adherent to their treatments according to 8-item morisky medication adherence scale. Occupational status and source of medical service or treatments were the most common factors associated antihypertensive medication adherence. Moreover, the status of blood pressure control was significantly associated with pattern of adherence.

\section{Sources of Support}

Not applicable.

\section{Authors' Contribution}

$\mathrm{GH}$ and $\mathrm{AA}$ designed, extracted, analyzed and interpreted the data. $\mathrm{GH}$ conceived the study; guided the design and supervised the whole research. GH also prepared the manuscript. Both authors read and approved the final manuscript.

\section{References}

1. Clinical practice guideline on management of hypertension. $\left(4^{\text {th }}\right.$ edn $)$.

2. Kearney PM, Whelton M, Reynolds K, Muntner P (2005) Global burden of hypertension: Analysis of worldwide data. Lancet 15-21.

3. Mayckel da Silva Barreto, Isabela Zara Cremonese, Vanderly Janeiro, Laura Misue Matsuda, Sonia Silva Marcon (2015) Prevalence of non-adherence to antihypertensive pharmacotherapy and associated factors. Rev Bras Enferm 68: $54-60$.

4. Alsolami F, Yu Hou X, Correa-Velez I (2012) Factors affecting antihypertensive treatment adherence: A saudi arabian perspective. Clinical Medicine and Diagnostics 2: 27-32.

5. Martin CS Wong, Kirin QL LiU, Harry Wang, Catherine LS Lee RN, Mandy WM Kwan, et al. (2013) Effectiveness of a pharmacist-led drug counseling on enhancing antihypertensive adherence and blood pressure control: A randomized controlled trial. The Journal of Clinical Pharmacology 53: 753-761.

6. (2003) World health organization. Adherence to long term therapies-evidence for action.

7. Candy D Kang, Prilla P M Tsang, Winson T L Li, Harry $H X$ Wang, Kirin Q L Liu, et al. (2015) Determinants of medication adherence and blood pressure control among hypertensive patients in Hong Kong. Int J Cardiol 250-257.

8. Hareri AH, Abebe M (2012) Assessments of adherence to hypertension medications and associated factors among patients attending tikur anbessa specialized hospital renal unit, addis ababa, ethiopia 2012. International Journal of Nursing Science 3: 16

9. Gelaw BK, Gelaw YK, Satessa GD, G/Mariam ET (2014) Assessment of adherence of patients with anti-hypertensive medication and factors for non-adherence in amhara region dessie referral hospital, ethiopia. International Journal of Chemical and Natural Science 2: 51-57.

10. Alexander T, Enguday S, Haregwoin A, Hiwot A, Tariku B (2006) Compliance and Factors related to treatment of chronic illness in adult population visiting Yirgalem Hospital 13-14.

11. Ambaw AD, Alemie GA, Yohannes SM, Mengesha ZB (2012) Adherence to antihypertensive treatment and associated factors among patients on follow up at University of Gondar Hospital, Northwest Ethiopia. BMC Public Health 12: 282.

12. Thomas AE, MA van der Sande, PJ Milligan, OA Nyan, JT Rowley, et al. (2009) Factors affecting compliance with antihypertensive drug treatment and required lifestyle modifications among hypertensive patients on Praslin Island.

13. MAB van der Sande, PJM Milligan, OA Nyan, JTF Rowley, 
WAS Banya, et al. (2000) Blood pressure patterns and cardiovascular risk factors in rural and urban Gambian communities. J Hum Hypertens 14: 489-496.

14. Morisky DE, Green LW, Levine DM (1986) Concurrent and predictive validity of a self-reported measure of medication adherence. Med Care 24: 67-74.

15. (2013) Pusczak analysis of sample size in customer surveys.
16. B Bhandari, M Bhattarai, M Bhandari, A Ghimire, PK Pokharel, et al. (2015) Adherence to antihypertensive medications: Population based follow up in eastern nepal, $\mathrm{Ne}-$ pal Health Res Counc 13: 38-42.

17. Iloh GUP, Ofoedu JN, Njoku PU, Amadi AN, Godswill-Uko EU (2013) Medication adherence and blood pressure control amongst adults with primary hypertension attending a tertiary hospital primary care clinic in Eastern Nigeria. Afr $\mathrm{J}$ Prim Health Care Fam Med. 